\author{
ARTIGO \\ dO https://doi.org/10.22481/praxisedu.v16i39.6407
}

\title{
A COMUNIDADE QUILOMBOLA DE QUEIMADAS: A LUTA PELO RECONHECIMENTO E VALORIZAÇÃO DA MEMÓRIA/HISTÓRIA
}

\author{
THE QUILOMBOLA COMMUNITY OF QUEIMADAS: THE STRUGGLE FOR THE \\ RECOGNITION AND VALUATION OF MEMORY / HISTORY
}

\begin{abstract}
LA COMUNIDAD QUILOMBOLA DE QUEIMADAS: LA LUCHA POR EL RECONOCIMIENTO Y VALORIZACIÓN DE LA MEMORIA/HISTORIA
\end{abstract}

Hayla Fernanda Moura Lima

Universidade do Estado da Bahia - Brasil

Dinalva de Jesus Santana Macêdo

Universidade do Estado da Bahia - Brasil

\begin{abstract}
Resumo: A escravidão no Brasil foi sempre uma temática estudada e questionada principalmente no que se refere à questão do trabalho, da resistência do negro, da economia, dentre outras vertentes, salientando que a mesma aconteceu de maneira diferenciada e com particularidades, diversificando conforme às regiões e interesses. O presente estudo buscou analisar como se deu o processo de reconhecimento da comunidade de Queimadas como remanescente de Quilombo. Por meio deste trabalho é analisado o processo de certificação e a importância da memória e história dos moradores para valorização de seus antepassados e afirmação do ser quilombola. A investigação foi realizada na comunidade Quilombola Queimadas localizada em Guanambi/BA, na região do Território Sertão Produtivo. Utilizamos como recursos metodológicos a entrevista semiestruturada com três lideranças quilombolas, análise do livro de ata da associação comunitária e observação durante as reuniões da associação. Mediante os resultados da pesquisa notou-se o forte papel da assistente social para o reconhecimento da comunidade como quilombola e o entrelaçamento das lideranças da comunidade para que a certificação fosse alcançada, ressaltamos também a carência de benefícios após o reconhecimento e a relevância da história da comunidade para a construção da afirmação da identidade.
\end{abstract}

Palavras-chave: Comunidade quilombola; Memória e história; Reconhecimento.

\begin{abstract}
Slavery in Brazil has always been a theme studied and questioned mainly with regard to the issue of work, black resistance, the economy, among other aspects, emphasizing that it happened in a different way and with particularities, diversifying according to regions and interests. The present study sought to analyze how the process of recognizing the Queimadas community as a remnant of Quilombo took place. Through this work, the certification process and the importance of the residents' memory and history for the appreciation of their ancestors and the affirmation of being quilombola are
\end{abstract}


analyzed. The investigation was carried out in the Quilombola Queimadas community located in Guanambi / BA, in the Territorial Productive Territory region. We used as methodological resources the semi-structured interview with three quilombola leaders, analysis of the community association's minutes book and observation during the association's meetings. Through the results of the research, it was noted the strong role of the social worker for the recognition of the community as quilombola and the intertwining of community leaders for the certification to be achieved, we also emphasize the lack of benefits after the recognition and the relevance of the history of the Community for the construction of the affirmation of identity.

Keywords: Quilombola community; Memory and history; Recognition

Resumen: La esclavitud en Brasil siempre ha sido una temática estudiada y cuestionada principalmente con respecto a la cuestión del trabajo, la resistencia del negro, de la economía, entre otros aspectos, destacando que la misma sucedió de manera diferente y con particularidades, diversificando según regiones e intereses. El presente estudio intentó analizar cómo se sucedió el proceso de reconocimiento de la comunidad de Queimadas como remanente de Quilombo. A través de este trabajo se analiza el proceso de certificación y la importancia de la memoria y la historia de los residentes para la valorización de sus antepasados y la afirmación del ser quilombola. La investigación fue realizada en la comunidad Quilombola Queimadas, ubicada en Guanambi/BA, en la región del Territorio Sertão Produtivo. Utilizamos como recursos metodológicos la entrevista semiestructurada con tres líderes quilombolas, análisis del libro de acta de la asociación comunitaria y observación durante las reuniones de la asociación. A través de los resultados de la investigación, se notó el fuerte papel del asistente social para el reconocimiento de la comunidad como quilombola y el entrelazamiento de líderes de la comunidad para que se pudiera lograr la certificación, también destacamos la carencia de beneficios después del reconocimiento y la relevancia de la historia de la comunidad para la construcción de la afirmación de la identidad.

Palabras clave: Comunidad quilombola; Memoria e historia; Reconocimiento.

\section{Introdução}

Os quilombos são muito importantes na constituição da história do Brasil, que se organizaram/organizam como formas de resistência e lutas de seus valores, histórias e culturas. Vários descendentes dos quilombolas encontram-se nos mesmos locais que viviam seus ancestrais, buscando a preservação de seus valores, saberes, costumes e tradições, que são passados de geração à geração, fortalecendo suas identidades e o seu patrimônio histórico e cultural.

Nesse sentido, este estudo ${ }^{1}$ buscou analisar como se deu o processo de reconhecimento da comunidade de Queimadas como remanescente de Quilombo, localizada no munícipio de Guanambi/Ba no Território de Identidade Sertão Produtivo. A certificação da comunidade

\footnotetext{
${ }^{1}$ Este artigo foi elaborado a partir de um Trabalho de Conclusão de Curso (TCC) de uma Especialização em Educação do Campo, vinculada à Universidade do Estado da Bahia, Campus XII de Guanambi, concluída em 2018.
} 
como quilombola foi publicada no Diário Oficial da União em 09 de junho de 2015. Assim sendo, foram delineados os seguintes objetivos específicos: - Verificar como aconteceu o processo de reconhecimento da comunidade como remanescente de quilombo; - Averiguar a concepção que as lideranças têm de quilombo; - Analisar a importância da memória e história para a valorização dos antepassados da comunidade quilombola de Queimadas.

Para a realização do estudo fizemos uma pesquisa bibliográfica seguida de uma pesquisa de campo por meio de entrevistas semiestruturadas com lideranças quilombolas, observações em reuniões da Associação Remanescente de Quilombo de Queimadas, conversas informais com moradores locais e análise do livro de ata da referida associação.

Dentre os entrevistados estão uma mulher e dois homens, sendo ambos casados, lavradores, com idades entre 39 e 55 anos, todos com filhos, dois evangélicos e um católico, apenas um com ensino médio completo e nenhum aposentado. Todas as entrevistas foram transcritas na íntegra com a retirada apenas de alguns termos repetidos e algumas correções gramaticais, não mudando o contexto e o sentido das falas. Para o tratamento dos dados utilizamos a análise de conteúdo na modalidade temática, pois nos possibilitou uma melhor compreensão dos significados imprimidos pelos sujeitos em relação ao objeto de estudo.

Este artigo está organizado da seguinte maneira: no primeiro momento, esta introdução, onde elencamos as indagações e objetivos, bem como os percursos metodológicos elencados de maneira sucinta. No segundo momento abordamos a questão da temática dos Quilombolas, destacando os aspectos históricos até os dias atuais, relatando a respeito da legislação brasileira frente aos direitos das comunidades quilombolas e do processo de titulação das comunidades quilombolas de maneira geral. No terceiro momento, apresentamos os aspectos históricos, culturais e contemporâneos da Comunidade Quilombola de Queimadas. No quarto momento, apresentamos as categorias de análise dos dados coletados em diálogo com o aporte teórico.

As categorias de análise foram organizadas em duas, na primeira relatamos sobre o processo de reconhecimento da comunidade como remanescentes de quilombo e os trâmites para o processo de titulação e a segunda apresentamos a memória e a história de Queimadas como valorização de seus antepassados.

No último momento, nas considerações finais apresentamos uma síntese interpretativa dos principais resultados, destacando a relevância e necessidade de estudos acerca do tema para melhor compreensão das lutas e dificuldades referentes a essas comunidades, pois 
possibilitam reflexões a respeito da história das resistências do povo negro e seus direitos "conquistados" na atualidade.

\section{Comunidades Quilombolas no Brasil}

Do século XVI até metade do século XIX, aconteceu de maneira legal no Brasil o regime político e econômico chamado escravismo colonial, sistema que apresentou início posteriormente a vinda dos portugueses no Brasil. Naquela ocasião, Portugal com negócios significativamente vantajosos junto ao Oriente, busca ampliar sua capacidade econômica, sendo assim ocupa novas terras, que constituem o Brasil. Muito antes da chegada dos portugueses, o solo brasileiro, já era povoado por várias tribos indígenas, correspondendo aos primeiros donos das terras (GOULARTE, 2000).

Após suas terras serem dominadas pelos portugueses, os índios lutaram incessantemente para evitar a apropriação portuguesa, entretanto, mesmo com muito conflito não conseguiram reprimir a ocupação. Muitos índios morreram, outros foram escravizados através do modelo de produção determinado pelos colonizadores (SILVA, 2009). Nessa situação, acontece uma diminuição da mão de obra indígena, por conta disso os portugueses procuram no tráfico dos negros a maneira de continuar em andamento o processo escravocrata no Brasil (GOULARTE, 2000).

Uma característica marcante da história dos negros foi a resistência frente à escravidão em meio a tantos maus tratos sofridos. A resistência dos africanos escravizados ocorreu de várias maneiras. Perante tanta violência e injustiça, para tentar escapar desses sofrimentos muitos escravos se matavam e outros partiam para quilombos, no qual tentavam uma nova vida.

Clovis Moura define quilombo como organização sociopolítica, em que acontece resistências e combates ao processo escravista. Visto que numa sociedade onde se favorece o sistema escravocrata, o escravo, “[...] pela sua posição no espaço social, para dinamizá-la tem de negá-la, já que não lhe oferecem possibilidades de ascensão capaz de modifica-la. Esta necessidade é que leva o escravo a se organizar em movimentos ou grupos de negação ao sistema" (MOURA, 1986, p. 11).

Conforme Arruti (2006, p. 82), “o termo 'remanescente', no caso dos quilombos, pode servir, ao final, como expressão formal da ideia de contemporaneidade dos quilombos". 
Sendo preciso fazê-los tornar flexíveis a fim de quê se tornassem perceptíveis, ocasionando uma ressemantização da qual fizesse sentido.

A palavra quilombo carrega, em si, um enorme contexto histórico transportado de lutas e significados, assim como incessantes resistências manifestadas ao modelo de sistema exigido, de acordo com Moura (1987, p. 31):

[...] não podemos deixar de ver o quilombo como um elemento dinâmico de desgaste das relações escravistas. Não foi manifestação esporádica de pequenos de pequenos grupos de escravos marginais desprovidos de consciência social, mas um movimento que atuou no centro do sistema nacional, e permanentemente.

Para tal, discutir sobre quilombos no Brasil quer dizer pensar acerca da identidade de todo brasileiro, por esse motivo enquanto se fala sobre as comunidades quilombolas na contemporaneidade, resulta no reconhecimento de seus costumes e história no Brasil, assim como a vasta população proveniente do continente africano, "Há trezentos anos que o africano tem sido o principal instrumento de ocupação e da manutenção do nosso território pelo europeu, e que os seus descendentes se misturam com o nosso povo" (NABUCO apud FREITAS, 1982, p. 10).

Segundo Munanga (2001), para resgatar o vínculo do quilombo brasileiro com o quilombo africano comprova sua relevância como maneira de resistência ao sistema escravocrata.

A luta dos movimentos sociais, em especial do movimento negro e de estudiosos e pesquisadores sobre a população afro-brasileira e quilombola possibilitou uma vasta parcela da população negra, pleitear o reconhecimento de seus espaços como quilombolas. Tal como a partir da Constituição Federal de 1988, os quilombolas passaram a ter direitos assegurados, inclusive a criação da Fundação Cultural Palmares ${ }^{2}$ (FCP) que foi uma grande conquista afrobrasileira.

A Constituição Federal de 1998, no art. 68 do Ato das Disposições Constitucionais Transitórias (ADCT), reconheceu às comunidades quilombolas direitos territoriais nestes termos: aos remanescentes das comunidades dos quilombos que estejam ocupando suas terras é reconhecida a propriedade definitiva, devendo o Estado emitir-lhes os títulos respectivos (PRIOSTE, 2016, p. 105).

\footnotetext{
2 Em 22 de agosto de 1988, o Governo Federal fundou a primeira instituição pública direcionada para melhoria e preservação da arte e da cultura afro-brasileira: a Fundação Cultural Palmares, entidade ligada ao Ministério da Cultura (MinC).
} 
Entretanto, são vários os estereótipos levantados ou desejados na demanda de encontrar nas atuais comunidades, ou que sejam nos sujeitos presentes, características genuínas dos africanos do passado.

A partir dessas discussões, embates e lutas, tendo em vista compreender quem são esses sujeitos de direitos reconhecidos pela Constituição Federal, o Decreto $n^{\circ} 4.887$, de 20 de novembro de $2003^{3}$, em seu artigo Art. $2^{\circ}$, consideram-se remanescentes das comunidades quilombolas

[...] os grupos étnico-raciais, segundo critérios de auto-atribuição[sic], com trajetória histórica própria, dotados de relações territoriais específicas, com presunção de ancestralidade negra relacionada com a resistência à opressão histórica sofrida.

Os quilombos são parte fundamental da História do Brasil, visto que os mesmos consistem em ambientes de resistência e lutas. Essa resistência também foi uma característica marcante durante a escravidão.

O processo de titulação das terras quilombolas, regimentado pelo Decreto 4.887 de 2003, se faz por muitas fases, partindo pela autoatribuição aos remanescentes, reconhecimento, demarcação e até mesma a titulação das terras. No primeiro momento em que se visa identificar as comunidades de remanescentes de quilombos, fica sob responsabilidade da Fundação Cultural Palmares (FCP). Até 2003, a titulação territorial (identificação e delimitação dos territórios), era atribuição da Fundação Cultural Palmares, no âmbito federal. Por conta do Decreto 4.887 de 2003, essa atribuição passou a ser do Instituto Nacional de Colonização e Reforma Agrária (INCRA), que se responsabiliza pela identificação, reconhecimento, delimitação, demarcação e titulação das terras que foram ocupadas pelas comunidades quilombolas. Este não é um processo simples ou "amigável", trata-se de um processo lento e burocrático, desta maneira muitas comunidades permanecem apenas com certificação de comunidades quilombolas, na primeira fase do processo.

Posterior ao início da autoatribuição étnica da comunidade e do processo administrativo, a Fundação Cultural Palmares emite a certificação como uma comunidade remanescente de quilombo. Em seguida, uma equipe técnica interdisciplinar formada por

\footnotetext{
${ }^{3}$ Destacamos que a partir de 2003, o governo do PT, em mandato o ex-presidente Luiz Inácio Lula da Silva, gerou programas de efetivação de políticas públicas, tais como Bolsa Família, Fome Zero e Brasil Quilombola, baseado no discurso do desenvolvimento da justiça social. Ambos com intuito, possibilitar a autonomia e inclusão dos sujeitos por meio das políticas afirmativas no ideário liberal.
} 
antropólogo, técnico de cadastro, agrônomo entre outros profissionais realizam práticas de atividades de campo para reconhecimento territorial, a partir da elaboração do Relatório Técnico de Identificação e Delimitação (RTID). No RTID há diversas informações, entre históricas, cartográficas, ambientais, socioeconômicas, dentre outras.

Após a conclusão do RTID, uma versão sucinta do mesmo é divulgada no Diário Oficial do Estado e no Diário Oficial da União, uma cópia disponível na prefeitura, do município onde se localiza a comunidade. Depois disso, num prazo de noventa dias, outros órgãos e agentes podem entrar em contradição a respeito do RTID.

Em seguida, a esse grande processo de julgamentos e acordos das contradições, o reconhecimento é publicado, apresentando os limites das terras quilombolas. No caso da terra, que foi reconhecida como quilombola, se for de posse particular, o Presidente da República irá publicar um Decreto de desapropriação e por fim é concedido um título comunitário que fica em nome da associação representante da comunidade.

Muitas comunidades quilombolas vêm lutando em prol da posse e titulação de suas terras, bem como por uma melhor qualidade de vida, pelos direitos à saúde, à moradia digna e a uma educação que respeite as suas especificidades étnico-culturais. Essas populações resistem e lutam pela sua cidadania formal e efetiva (MACÊDO, 2015).

A primeira comunidade quilombola a ser titulada no Brasil foi a comunidade de Boa Vista, no Pará, em 20 de novembro de 1995, sete anos depois da Constituição Federal de 1988, foi reconhecido o direito à propriedade de suas terras por meio do artigo 68 do ADCT, este artigo é conduta com resultados jurídicos rápidos, pois institui encargo ao Estado de propagar práticas designadas à titulação de terras que pertencem as comunidades remanescentes de quilombos.

Dados da Fundação Cultural Palmares (FCP), apontam para 3386 comunidades certificadas conforme portaria 138 de 03 de agosto de 2019. Todavia, segundo o movimento negro, o Brasil tem mais de 5000 comunidades quilombolas.

Esses dados revelam que algumas comunidades estão em processo de organização para assegurar seus direitos às terras em que vivem. A demora do processo ocorre por conta do poder público. Essas comunidades estão espalhadas por quase todos os estados, exceto os territórios que abrange, atualmente, os estados do Acre, Roraima e do Distrito Federal, nos quais, de acordo a Fundação Cultural Palmares (FCP), não teria remanescentes de comunidades quilombolas. 
Entre os estados brasileiros, a Bahia é o estado com maior número de comunidades quilombolas, com um total de 736 comunidades certificadas pela Fundação Cultural Palmares. No Estado da Bahia pode-se reconhecer duas áreas amplas que abrangem a maior parcela de comunidades. A primeira é reconhecida no Recôncavo Baiano. Sua existência pode estar relacionada, principalmente, com os engenhos de cana-de-açúcar que existiram por séculos nesta região fazendo uso do trabalho escravo. A segunda é reconhecida no Sudoeste do Estado mais precisamente ao Norte. Certamente, um dos maiores motivos para a colonização da referida região foi a exploração do ouro e, continuamente, o cultivo do algodão. Assim:

Os quilombos, organizações que se constituíram como uma das expressões do desejo de liberdade, assumiram feições organizacionais que levaram em conta os fatores geográficos, ecológicos e o campo de forças sociais próprios ao momento de insubordinação e ocupação do território. (SILVA, 2000, p. 273).

Para Dutra (2007), as comunidades de Rio das Rãs e Araçá Cariacá, são grandes impulsionadoras e exemplos de luta do movimento quilombola na história da Bahia, sendo vistas mundialmente. De acordo com Dutra (2007, p. 143),

O reconhecimento dos territórios quilombolas na região do Médio São Francisco e do Alto Sertão Baiano não levou as populações envolvidas a solucionar todos os seus problemas. Estes continuam na maioria dos territórios, pois ainda existe a falta de infraestrutura, de melhores condições de produção e comercialização dos produtos bem como problemas ligados a questões da saúde, da educação e do abastecimento de água potável.

Esse cenário exige a urgência de investimentos de políticas públicas para a melhoria da qualidade de vida desses povos. Assim, notamos o grande descaso que existe com essas comunidades, e reforçamos que apenas a titulação não é suficiente. Ilka Leite (2008) reconhece que as incoerências presentes entre a legislação e a sua execução ativa neste momento tem sido o maior obstáculo, já que o mecanismo legítimo de reconhecimento de terras quilombolas e titulação das mesmas não foi capaz de reprimir a ações de domínio de terras e expropriação e, transformar a prática de exclusão e precariedade que encontram-se a população rural negra.

\section{Comunidade Quilombola de Queimadas no Território de Identidade Sertão Produtivo}

O Território de Identidade é um modelo de crescimento, que reúne municípios com semelhanças históricas, econômicas, sociais, geográficas, entre outras, criada pelo Ministério 
do Desenvolvimento Agrário (MDA), com início em 2003. No ano de 2007, a Secretaria de Cultura do Estado da Bahia aderiu essa divisão do território baiano em 26 Territórios de Identidade e reconheceu a existência de 27 Territórios de Identidade, compostos por meio das particularidades de cada região. Atualmente são reconhecidos 27 Territórios de Identidade na Bahia, com o propósito de incentivar a contribuição e vínculo regional com base no crescimento.

O Território de Identidade do Sertão Produtivo é formado por 20 municípios: Brumado, Caculé, Caetité, Candiba, Contendas do Sincorá, Dom Basílio, Guanambi, Ibiassucê, Ituaçu, Iuiu, Lagoa Real, Livramento de Nossa Senhora, Malhada de Pedras, Palmas de Monte Alto, Pindaí, Rio do Antônio, Sebastião Laranjeiras, Tanhaçu, Urandi e Tanque Novo.

No Território de Identidade existem $55^{4}$ comunidades quilombolas, dentro os 20 municípios, apenas 10 possuem comunidades certificadas como remanescentes de quilombos. Caetité- 13; Candiba- 01; Contendas do Sincorá- 1; Guanambi-2; Ibiassucê- 01; Livramento de Nossa Senhora- 15; Lagoa Real- 01; Palmas de Monte Alto- 17 e Tanhaçú - 02, Pindaí02 .

Ao falar sobre comunidades quilombolas remanescentes de quilombos, é importante recuperar seus vínculos com a formação da população baiana e suas colaborações, com a finalidade valorizá-las. Desta maneira, faremos uma explanação sobre a história da comunidade Quilombola de Queimadas.

Com aproximadamente 118 famílias, em sua maioria os moradores da comunidade são descendentes dos primeiros moradores de Queimadas e alguns de comunidades vizinhas. De acordo conversas informais junto aos moradores da comunidade Quilombola de Queimadas, bem como acesso ao relato histórico ${ }^{5}$ da comunidade, as famílias negras que moram na comunidade, durante sua história lutaram e resistiram por um território próprio, em que ergueram uma herança cultural e histórica do qual vem se refletindo desde seus descendentes.

A apropriação da terra se deu por meio de compra de terreno por parte dos primeiros moradores da comunidade, o Senhor José e a Senhora Maria Antônia conhecidos como "Zé Véi” e "Iáiá". Corroborando com essa premissa, Santos (2017, p. 100) aponta que,

\footnotetext{
${ }^{4}$ Vale ressaltar que esses dados foram coletados a partir do site da Fundação Cultural Palmares. Foi preciso contar a quantidade de comunidades certificadas em cada município para dar este total de 55 comunidades quilombolas. Esse número pode variar devido a não atualização do site.

${ }^{5} \mathrm{O}$ relato histórico da comunidade foi fornecido pelo vice-presidente da associação da comunidade Quilombola de Queimadas, onde contém informações sobre todo percurso dos primeiros moradores da comunidade, bem como aspectos culturais da mesma.
} 


\begin{abstract}
A história de Queimadas se difere, ao menos em alguns aspectos, da história de muitas outras comunidades quilombolas do país. Enquanto várias delas encontram-se em áreas fronteiriças ou áreas de conflitos fundiários e pleiteiam a certificação visando a regulamentação dos seus territórios, Queimadas tem a especificidade de ser um quilombo que possui documento de compra da terra. Assim, a área ocupada por seus moradores pertence à família desde o ano de 1917 e foram transferidas aos seus descendentes através de herança.
\end{abstract}

A comunidade de Queimadas era conhecida como Lagoa do Major, a origem desse nome, deu-se pelo fato de por volta do ano 1915 o coronel Major, que comandava todo território de Vitória da Conquista-Bahia à Palmas de Monte Alto-Bahia, sendo dono de toda terra, do mesmo modo era quem tinha domínio sobre todo povo que residia nas terras em termos de subsistência e trabalho.

Após alguns anos o coronel Major encaminhou às terras, onde hoje é localizada a comunidade Quilombola de Queimadas, um casal de seus africanos escravizados, José e Maria Antônia onde ali moraram em uma cabana construída por casca de pau por anos, juntamente com seus onze filhos que tiveram ao longo dos anos. José e Antônia trabalhavam na fazenda do coronel Major, localizada na fazenda Lameirão, onde ficavam todo o dia retornando no final da tarde para Lagoa do Major que situava a $15 \mathrm{~km}$ de distância da fazenda. Depois de algum tempo, José conseguiu comprar uma parte da terra por volta de sua cabana, onde desflorestou por meio de Queimadas dando origem ao nome da comunidade Quilombola de Queimadas.

A família de José foi crescendo e continuando na localidade de Queimadas trabalhando para o coronel Major, também plantavam mandioca, milho e produziam a farinha e o fubá para alimentação, algodão para produção de um vestuário denominado riscado, embornal e coxinilho para colocar sobre os burros no momento de montar. Com o passar do tempo os filhos de José foram se casando com moradores de comunidades próximas e sendo construídas novas casas, continuando a exploração pelo trabalho.

Diante de todas as dificuldades, de uma vida sofrida, os moradores da localidade arranjavam tempo para festejos tais como reisado, valsa, samba de roda, xote e rancheiro. E por volta dos anos 60 as coisas foram se modificando, mesmo diante do trabalho escravo árduo, os moradores se deslocavam para outras localidades mais afastadas e conseguiam trazer benefícios para comunidade, inclusive com o tempo passaram a construir suas casas de um material conhecido naquela época como adobão. 
Até os dias de hoje, muitos homens e mulheres se deslocam durante a madrugada, em transporte muitas vezes precário, para fazendas distantes para trabalhar como boia fria, regressando no final da tarde para suas casas, após tanto tempo, vê-se ainda resquícios de mão de obra escrava.

\subsection{A luta pelo reconhecimento da comunidade como quilombola}

Através da Constituição Federal de 1998, as comunidades Quilombolas começaram a ser escopo de pesquisas e legislação. Com essa nova perspectiva, essas comunidades passaram a ter um fundamento legal evidenciado por meio dos conjuntos de leis, diante das lutas pelo reconhecimento como remanescentes de quilombos e fundiário.

Nesse cenário, a temática dos territórios quilombolas está sendo debatida nos dias de hoje se fazendo evidente nos movimentos do meio rural. Sobre esse ponto de vista, Leite (2000, p. 334), afirma que,

Nos últimos vinte anos, os descendentes de africanos, chamados negros, em todo o território nacional, organizados em Associações Quilombolas, reivindicam o direito à permanência e ao reconhecimento legal de posse das terras ocupadas e cultivadas para moradia e sustento, bem como o livre exercício de suas práticas, crenças e valores considerados em sua especificidade.

Por meio desse respaldo, em análises feitas no livro de ata da Associação Remanescente de Quilombo de Queimadas, foi possível perceber que em março de 2014 começaram os questionamentos na comunidade sobre remanescentes de Quilombos através da assistente social do município, relacionados ao processo de certificação, visto que anteriormente a isso havia conversas no âmbito da comunidade, porém sem avanços. Em uma reunião ordinária da associação comunitária no dia 12 de setembro de 2014, o presidente Sr. Manoel (presidente da época) destacou a visita da assistente social juntamente com um pessoal, que vieram da cidade de Salvador/BA, onde os mesmos buscavam informações para o reconhecimento da comunidade como remanescentes de Quilombos.

Em entrevista com Sr. Manoel, vice-presidente da Associação de Queimadas, quando questionado sobre o processo de certificação da comunidade, ele corrobora com os dados coletados no livro de ata da associação. 
A partir da assistente social que veio fazer uma visita aqui e daí ela me fez perguntas sobre como é que surgiram essas pessoas aqui. Porque onde meu Bisavó Zé Marque morava ${ }^{6}$, lá era escravo mesmo, a mãe do meu avô, foi pegada no mato, foi índia que os fazendeiro pegou pra criar, minha vó era 'escrava' e índia Tapuia ${ }^{7}$, lá de Igaporã, naquele morrão que tem lá pró lado de lá, onde era chamado de Bonito. (Seu Manoel, entrevista dia 25/06/2018).

Em consonância com a fala do Sr. Manoel, Dona Rosa, moradora da comunidade de Queimadas, quando questionada a respeito da certificação, ela nos informa:

\begin{abstract}
Moça, eu não sei lhe falar como foi que aconteceu, que veio esse negócio de 'canhambola', quando nós percebemos, já estávamos em reunião com o povo de Guanambi [...]. Outro dia as meninas estavam conversando com a gente aí no prédio ${ }^{8}[\ldots]$ que vieram aqui uns rapazes de Guanambi e falaram nós podíamos cadastrar Queimadas como 'canhambola', 'porque o povinho é tudo pretinho'. Aí todo mundo aceitou, agora passou ser esse negócio de 'canhambola'.[...]. Só se sabe que é por conta da cor do pessoal, que é tudo preto [...] (Dona Rosa, moradora da comunidade, entrevista dia 23/06/2018).
\end{abstract}

Nas falas do Sr. Manoel e Dona Rosa, é visível o papel da assistente social do município durante a certificação da comunidade, visto que a partir do engajamento da mesma o processo começou a ter andamento, por meio de questionamentos feitos por ela, pois anteriormente a isso a comunidade por si não conseguiu dá seguimento, como foi relatado pelo presidente atual da associação. “Antes já tinha conversas, mas não foi avante, depois de Rose que foi pra frente". (Paulo, Entrevista dia 22/06/2018). Assim fica notório o empenho e interesse da assistente durante o processo, bem como a importância da autoatribuição, sendo que nem todos os moradores se autoatribuem como quilombola.

Segundo Cardoso (2013, p.100) o reconhecimento como quilombola não implica apenas nas lutas por terras, mas "acolher a imagem negativa que se constrói sobre a população negra, para si, ao longo da história”.

Diante da fala, anteriormente, de Dona Rosa, ressaltamos que nem sempre o negro é Quilombola, ela atribui o "ser quilombola" a cor negra, não se atentando a todo contexto histórico complexo que essa identidade carrega, pois é importante tomar conhecimento do processo de construção da identidade negra na sociedade brasileira.

\footnotetext{
${ }^{6} \mathrm{O}$ bisavô do Sr. Manoel, Zé Marques, veio de uma vila cujo nome era Bonito, naquela época, onde atualmente está situado o município de Igaporã/Ba.

7 “Tapuia é um termo que foi utilizado, ao longo dos séculos, no Brasil, para designar os índios que não falavam a língua tupi. Disponível em: https://pt.wikipedia.org/wiki/Tapuias. Acesso em: 24 de set. 2018.

${ }^{8}$ As reuniões da associação da comunidade acontecem no prédio escolar, visto que a mesma não possui sede até o momento.
} 
Dando continuidade à coleta de dados, através da análise do livro de ata da associação, evidenciamos que em setembro do ano de 2014, os técnicos visitaram a comunidade, para dá início ao processo de certificação juntamente com a assistente social do município, averiguando as possiblidades de reconhecimento, e deste modo após um ano e três meses conquistaram a certificação, a qual foi reconhecida pela Fundação Cultural Palmares, em 05 de junho de 2015, como uma comunidade remanescente de quilombo. Queimadas é a primeira comunidade reconhecida como quilombola do município de Guanambi-Ba, além da certificação, é muito importante o reconhecimento de seus valores culturais, saberes e história.

Para Paulo, o presidente da Associação Remanescente de Quilombo de Queimadas, o caminho percorrido até que eles alcançassem as condições presentes de reconhecimento foi demorado.

Muito tempo já tinha a luta da gente né, muitos anos atrás. Agora nós achamos essa oportunidade nessa gestão de Charles Fernandes, primeira gestão dele. [...] Manoel que era presidente da associação na época foi muito ativo, lutou muito, sei que foi através de muita luta que conseguimos, não foi fácil. (Paulo, presidente da associação, entrevista dia 22/06/2018).

Fica evidente o empenho e luta das lideranças da comunidade, em prol de seu reconhecimento, visto que é uma luta de todos em busca de um bem comum. Reforçando essa ideia, Cardoso (2013, p. 102 e 103), destaca que "a associação quilombola possui princípio étnico e tem o poder de condensar os desejos dos sujeitos [...] isso imprime força à organização política local”.

Evidenciamos que durante o processo de reconhecimento é de grande importância o apoio dos moradores mais velhos da comunidade, pois os mesmos carregam em si uma enorme bagagem de conhecimentos sobre a história de seus antepassados, reforçando essa ideia, Dona Rosa retoma,

[...] eles $^{9}$ foram na casa de Chica, na casa de madrinha Bêja, de Tia Lia ... quem foi o outro aqui? [...] Tiraram foto, tá até no vídeo ${ }^{10}$. Madrinha Beja, Tia Lia e Chica, teve outra pessoa, não sei se foi Tassilo, foram quatro pessoas que explicaram de onde é que viemos, donde que veio o pessoal de Seu Cândido e o pessoal de Zé Marques, [...] só procuraram essas pessoas mais velhas que sabiam explicar [...] (Dona Rosa, moradora da comunidade, entrevista dia 23/06/2018).

\footnotetext{
9 Equipe de técnicos responsáveis pelo processo de reconhecimento da comunidade de Queimadas como remanescente de Quilombo.

${ }^{10} \mathrm{O}$ vídeo faz parte de um relatório que foi feito durante o processo de certificação, onde encontra-se a história da comunidade relatada por alguns moradores.
} 
A memória tem grande relevância para o reconhecimento de uma comunidade, visto que ela oferece informações para as pessoas, ainda que não tenham visto ou participado de tais acontecimentos, LE GOFF (2003).

As comunidades quilombolas de modo geral, que não é o caso de Queimadas, atualmente, pelejam em luta para garantir o direito a permanência e acesso as terras que tradicionalmente lhes foram negadas, tal como propagação de seus meios de vida peculiares.

A comunidade de Queimadas está em processo de demarcação de seu território, evidenciamos que em agosto de 2016, com base nas leituras do livro de ata da associação, representantes da Coordenação de Desenvolvimento Agrário (CDA) e o Núcleo de Ações em Quilombos (NAQ), estiveram em reunião extraordinária na Associação de moradores de Queimadas para esclarecer à importância das comunidades Quilombolas e a necessidade de se fazer a regularização fundiária, assim como a necessidade de fazer o planejamento da área a ser demarcada. Porém, podemos notar que em abril de 2018, em assembleia geral na associação, mais uma vez a assistente social, o representante da secretaria de agricultura e o INCRA abordaram sobre a demarcação das terras que ainda não foram realizadas, atentando aos moradores que a comunidade vem perdendo muitos benefícios por conta disso, sobre este processo o presidente da associação da comunidade de Queimadas, relata que,

Tá no processo aí, nós fizemos a solicitação, já mandos, só que o processo é lento. A assistente social Rose, todo dia tá ligando pra nós, perguntando. Isso aí demora, estamos perdendo de ganhar benefícios né, que através da titulação das terras é que vai vim vários benefícios para a comunidade. (Entrevista dia 22/06/2018).

O processo para titulação das terras quilombolas é lento e requer muito empenho por parte da comunidade, pois são muitas as exigências para conquistar a permanência legal na terra. Conforme Ilka Leite, “[...] as mais bem sucedidas experiências de implementação do artigo 68 tem sido aquelas em que se conseguiu estabelecer uma parceria entre comunidades, entidades governamentais e os diversos agentes locais favoráveis à regularização" (LEITE, 2000, p. 348).

Diante dessas reflexões, compreendemos que além da comunidade, é necessário haver vontade política e investimento por parte do poder público local, para que possa ocorrer a demarcação das terras quilombolas, o que poderá possibilitar aos sujeitos a garantia de direitos, para a inserção ao meio social, tendo em vista uma vida mais digna e cidadã. 
Atentamos pela valorização da comunidade em relação aos benefícios já conquistados e a luta para que seus direitos sejam cumpridos, visando também a preservação de seus valores culturais e históricos, sendo um dos maiores benefícios que possam vir a conseguir.

\title{
3.2 Valorização dos seus antepassados: preservando a memória e história da comunidade
}

O sujeito constitui sua identidade por meio dos sentidos que ela incumbe a uma prática cultural. Sendo assim, a identidade é capaz de ser deliberada como aquilo que atribui sentido a um grupo/povo. A identidade étnica é reconhecida em grupo, por meio de preservações de valores sociais e culturais. Deste modo, nota-se que a formação dos quilombos durante a era colonial, perpetua na atualidade, mostrando uma espécie de resistência à identidade étnica. Segundo Munanga,

\begin{abstract}
A identidade é uma realidade sempre presente em todas as sociedades humanas. Qualquer humano, através de seu sistema axiológico sempre selecionou alguns aspectos pertinentes de sua cultura para definir-se em contraposição ao alheio. A definição de si (autodefinição) e a definição dos outros (identidade atribuída) têm funções conhecidas: a defesa da unidade do grupo a proteção do território contra inimigos externos, as manipulações ideológicas por interesses econômicos, políticos, psicológicos, etc. (1994, p. 177-178).
\end{abstract}

A identidade possibilita que o sujeito se junte à comunidade se impondo de maneira diferente perante a sociedade. Conforme Gohn (2008, p. 32), ao associar identidade com reconhecimento "inicia-se o processo de dar sentido às ações, individuais ou coletivas. Nesse processo, os indivíduos transformam-se em sujeitos". Ao serem vistos enquanto sujeitos de direitos, os quilombolas começam a atribuir significados às suas práticas, visto que encontram-se acessíveis às novas possibilidades e modificações no cenário econômico e cultural que acontecem em meio a comunidade e no exterior da mesma.

Na comunidade Quilombola de Queimadas não deixa de ser diferente, onde pôde-se notar, no momento das entrevistas, uma forte valorização de seus antepassados. Sr. Manoel, vice-presidente da associação comunitária, quando questionado a respeito da história da comunidade, ressalta:

[...] moça, eu ainda conheci a minha bisavó, eu era bem pequenininho e ela me contou algumas histórias de quando ela chegou aqui e eu gravei, os mais 
velhos eu tenho certeza que são capazes de saberem direitinho, [...]. Eu era muito pequeno e curioso pra saber algumas coisas, eles me contaram e eu gravei, algumas coisas eu sei falar [...]. (Entrevista em 25/06/2018).

Desse modo, nota-se quão relevante é conhecer as histórias e vivências dos nossos antepassados, e que muitas vezes esse conhecimento faz com que possa ajudar na preservação das tradições e valores de determinados grupos, como acontece em Queimadas. De acordo com Santos (2017, p. 98) "a memória se torna um recurso valioso a ser acessado, uma vez que ela contém e guarda as raízes dos pertencimentos étnicos da comunidade e os fundamentos da identidade do grupo.”.

Ainda com relação à construção da identidade para valorização de um grupo, enfatizamos a importância de conhecer a história do meio em que se vive,

[...] foi formando pessoas aí né e foi só aumentando o povo e tá aí, através desse povo. Às vezes os mais novos não sabem, mas os antigos têm muita história pra contar, como começou as Queimadas, pessoal veio de fora. [...]. Eu mesmo só lembro de Zé Marques e Cândido né, que são duas famílias, que tinham aí, depois foram aparecendo filho, neto, bisneto, juntando uma família na outra só aumentando, só que isso vem de lá atrás, a história. (Paulo, presidente da associação, entrevista em 22/06/2018).

A preservação da memória se fez relevante para consolidação da ligação pertencente ao sentimento de identidade da comunidade com o local,

A memória, essa operação coletiva dos acontecimentos e das interpretações do passado que se quer salvaguardar, se integra, como vimos, em tentativas mais ou menos conscientes de definir e de reforçar sentimentos de pertencimento e fronteiras sociais entre coletividades de tamanhos diferentes: partidos, sindicatos, igrejas, aldeias, regiões, clãs, famílias, nações etc. (POLLAK, 1989, p. 9).

Dessa maneira, a memória consegue ser compreendida no ponto de vista social e coletivo, levando em consideração o individual. O preservar da memória de um grupo é significante para elaboração de novas compreensões dos antepassados e na preservação da identidade grupal.

Em Queimadas, a maioria dos moradores é da própria comunidade, descendentes dos primeiros moradores e alguns de comunidades vizinhas. Há uma forte presença da ligação familiar, bem como o entrelaçamento dessas pessoas na comunidade. Dona Rosa, moradora da comunidade de Queimadas, ressalta ao ser questionada sobre os moradores da comunidade, "É tudo daqui, tem uns pouco de outro lugar, mais é tudo perto, igual o marido da menina de 
'cumade' Lôra é daqui das Aroeira, Alcíde não é daqui de dentro mais é dali de perto, da Lagoa da Onça, tem um lote aí, mais é tudo de perto.” (Entrevista em 23/06/2018).

A ideia de pertencimento, tanto familiar quanto étnico, carrega em si à existência dos traços comuns em meio aos quilombolas, evidenciando uma forte parcela de moradores, sendo pais, esposas, filhos e irmãos, que ali permanecem e colaboram para a memória e identidade da comunidade, ou de comunidades vizinhas que ali se ajuntam e enraízam constituindo um só povo. Deste modo, “A identidade não é algo inato. Ela se refere a um modo de ser no mundo e com os outros." (GOMES, 2005, p. 41).

Corroborando com essa ideia, conforme trecho da entrevista com o presidente da associação, Paulo, enfatiza que, “A maioria são todos daqui. Mas também vieram de outras comunidades, como de Morro de Dentro ${ }^{11}$, que tem o mesmo perfil de Queimadas. [...]. Agora nas Queimadas é difícil sair um daqui”.(Entrevista dia 22/06/2018).

Essas pessoas que vieram de fora se reconhecem como quilombolas? "Ah, reconhecem, todos que moram aí, até esses novatos que vão chegando também tudo vai se reconhecer, por que ser quilombola é muito importante" (Entrevista em 22/06/2018).

Durante as observações nas reuniões da associação e em análise ao livro de ata, foi perceptível que muito se questionou e se questiona a respeito dos benefícios que uma comunidade Quilombola pode possuir, mas fica evidente a falta de um diálogo mais aprofundado $^{12}$ acerca da questão de "ser quilombola", principalmente por meio das pessoas que vêm de fora da comunidade.

Quando indagada sobre seu ponto de vista do que vem a ser Quilombola, Dona Rosa responde:

Minha fia [risos], sei lá, até hoje eu tô sem saber, o que vem a ser 'canhambola', porque a gente pergunta eles ${ }^{13}$, só falam que é por causa da qualidade preta, gente fala moreno, mas não pode falar que é moreno tem que falar de cor preta. Aí agora não sei porque motivo, se vai ser só por causa da qualidade. (Entrevista dia 23/06/2018).

O relato desta moradora evidencia a dificuldade em compreender-se como quilombola. Para Paulo, presidente da Associação Remanescente de Quilombo de Queimadas,

\footnotetext{
${ }^{11}$ A comunidade Morro de Dentro está situada no mesmo município que Queimadas, possuindo um perfil semelhante a comunidade Quilombola pesquisada, fazendo com que a mesma possa vir a ser reconhecida como comunidade remanescente de Quilombo.

${ }^{12}$ Referimos ao termo "aprofundado", pois, de acordo estudos no livro de ATA e entrevistas, foram discutidos de uma maneira breve, em poucos momentos, a respeito da temática nas reuniões da associação comunitária de Queimadas.

${ }^{13}$ Eles: pessoas responsáveis pelo processo de certificação e demarcação da comunidade como Quilombola, aqueles que de alguma forma estão adentrando alguns espaços na comunidade com este objetivo.
} 
quando questionado, durante a entrevista, sobre sua concepção ao ser quilombola, ele relatou "Bom, quilombola acho que é descendente 'de escravo'14, da escravidão, igual aí nas Queimada, aí tem descendente de escravo também, dos bisavós de Seu Manoel mesmo, tataravós que vem de origem escrava [...]”. (Entrevista com Paulo, presidente, em 22/06/2018).

Nota-se nas três entrevistas realizadas, em relação ao questionamento do ser Quilombola, algumas semelhanças e disparidades nas repostas, algumas vezes um sentimento de dúvida e ao mesmo tempo uma compreensão sendo constituída. Nessa linha o vicepresidente da associação, Sr. Manoel, destaca:

Quilombola significa um povo que enfrentou muitas das vezes a batalha sem recuar e agora saiu esse direito perdido, que muitas das vezes não tinha essa alforria. Eles eram escravos. Quilombola eu comparo como uma liberdade, mesmo direito que os outros têm, em busca de um direito perdido [...] (Entrevista em 25/06/2018).

Os dados apontam também a carência de práticas formativas ${ }^{15}$ envolvendo os moradores para um melhor entendimento do "ser quilombola". Atividades que possam ocorrer em espaços que forneçam momentos participativos de maneira coletiva, com o objetivo de troca de saberes e aquisição de conhecimentos de ambos envolvidos.

Por vezes a dificuldade na construção da identidade quilombola também está relacionada ao enraizamento do racismo e preconceito na nação brasileira assim como no passado, evidenciando de várias maneiras e em diferentes espaços, sendo que o mesmo acaba impossibilitando o sujeito de se reconhecer.

É possível perceber, em meio à análise do livro de ata da Associação Comunitária, observações e entrevistas, quão importante cada indivíduo se autoafirmar como quilombola para que o conceito de identidade étnica de Quilombo possa se concretizar. Aos poucos a identidade quilombola em Queimadas está sendo construída. A autoafirmação como quilombola, quer dizer previamente, como apresenta Arruti (2006), "se descobrir", reconhecendo a importância de sua etnia e entrelaçando-se a ela, aceitar-se, se desapropriar de "definições” negativas que lhes foram impostas.

Reconhecemos a importância do papel da escola, sendo que a mesma tem uma enorme função na contribuição do processo de valorização e construção da identidade, bem como a

\footnotetext{
${ }^{14}$ Entendemos como descendente de negros escravizados.

${ }^{15}$ Não há na comunidade escola, os estudantes têm de se deslocar para o distrito, pois a escola que ali existia foi extinta com o processo de nucleação das escolas no campo no município de Guanambi, que iniciou-se no ano de 2005, com o fechamento de 103 escolas no meio rural.
} 
desmistificação do mito da democracia racial, que é entendido por Gomes (2006, pg. 57) como "uma corrente ideológica que pretende negar a desigualdade racial entre os brancos e negros no Brasil como fruto do racismo, afirmado que existe entre estes dois grupos raciais uma situação de igualdade de oportunidade e de tratamento.". Sendo que, além da "unidade nacional" faz-se necessário também que haja uma "democracia racial brasileira" (MUNANGA, 2003, p.15).

Atualmente já existem políticas públicas ${ }^{16}$ específicas para os quilombolas. Destacamos que essas políticas foram fruto de lutas intensas com o intuito de minimizar as desigualdades em consequência ao período escravocrata. Em suma, esses direitos nem sempre são cumpridos ou raramente são, como exemplo a comunidade de Queimadas, onde os estudantes precisam deslocar até o distrito de Mutãs para estudarem, visto que não possui escolas na comunidade.

Nesse contexto, as Diretrizes Curriculares Nacionais da Educação Escolar Quilombola preconizam que as escolas situadas nas comunidades quilombolas ou escolas que atendem estudantes oriundos desses territórios precisam garantir que o currículo escolar e as práticas educativas dialoguem com os saberes, as práticas, histórias e culturas dessas populações sem hierarquização e estereótipos, para que possam contribuir de maneira significativa no processo de construção da identidade étnico-racial dos educandos (MACÊDO, 2015).

Nessa perspectiva, a educação escolar pode auxiliar no empoderamento dos quilombolas de Queimadas, tanto das crianças como dos jovens, visto que a identidade quilombola ainda vem sendo construída, e o entrelaçamento com os antepassados é algo muito forte dentro da comunidade, isso tem ajudado no processo de reconhecimento. Fazendo-se relevante, tais aspectos, para prosseguirem na luta, a fim de melhores condições de vidas e efetivação dos seus direitos.

\section{Considerações}

Este estudo buscou analisar como se deu o processo de reconhecimento da comunidade de Queimadas como remanescente de Quilombo e a relevância da memória e da história dos antepassados para que a comunidade se reconheça como quilombola.

${ }^{16}$ Lei 10.639/03 e lei 11.645/05, consultar <http://www.planalto.gov.br/ccivil_03/Leis/2003/L10.639.htm> e <http://www.planalto.gov.br/ccivil_03/_ato2007-2010/2008/lei/111645.htm>, para maiores informações (BRASIL, 2018). 
No decorrer da pesquisa, evidenciou-se o quanto as organizações do povo negro lutaram em prol de melhores qualidades de vida e educação. Lutas que culminaram em alguns direitos legais, garantidos a esses sujeitos, mas que em vezes não são cumpridos. Deste modo, as comunidades quilombolas continuam em luta contra os estereótipos e preconceitos sem desfrutar de muitos direitos que lhes pertencem.

Dessa maneira, as experiências vivenciadas no campo de estudos, a análise ao livro de ata e as entrevistas evidenciaram que durante o processo de reconhecimento da comunidade Queimadas como remanescentes de quilombo, a assistente social do município, a comunidade e o poder público municipal envidaram esforços para que o reconhecimento ocorresse. Assim, o processo de reconhecimento da comunidade Queimadas, diferente de outras comunidades quilombolas foi amparado tanto pela comunidade quanto pela esfera pública municipal.

Os moradores de Queimadas se unem para que possam ter seus "direitos” garantidos, em conversa com o presidente atual da associação ele enfatiza que: "Seu Manoel, hoje é o vice-presidente, ele tá sempre cobrando, não para de cobrar... nós faz de tudo né, a gente quer ver as Queimada desenvolver.”(Paulo, presidente da associação, entrevista 22/06/2018).

Nos momentos das reuniões também foi perceptível um forte empenho das lideranças Quilombolas, visto que o diálogo e a luta continuam para que o processo de titulação aconteça.

Os resultados apontam também o quão são relevantes a memória e a história para o reconhecimento das comunidades quilombolas, visto que em Queimadas isso foi fator importante para que a certificação fosse alcançada. Onde notamos uma forte valorização dos antepassados e dos valores mantidos por eles. Todavia a compreensão do "ser quilombola" ainda encontra-se em construção. Sendo essencial para o entendimento acerca do reconhecimento da comunidade como quilombola, pela titulação das terras, bem como a manutenção das tradições e costumes da comunidade.

Ratificamos que o tema é de suma importância, pois nos possibilitou uma reflexão histórica a respeito da resistência negra, dos quilombos, das lutas, conquistas, das dificuldades enfrenadas em relação às questões de reconhecimentos, títulos de suas terras e avanços de seus direitos. Desse modo, os resultados da pesquisa apontam a necessidade de implementação de políticas públicas em Queimadas, com relação à saúde, educação, saneamento básico, estrutura e serviços.

Portanto, a pesquisa buscou contribuir com estudos contextualizados para um maior entendimento e atenção acerca da temática estudada. 


\section{REFERÊNCIAS}

ARRUTI, José Maurício Andion. Mocambo: Antropologia e história do processo de formação quilombola. Bauru: Edusc, 2006.

BRASIL. Constituição da República Federativa do Brasil. Diário Oficial, 1988.

BRASIL. Ministério da Educação. Secretaria Especial de Promoção da Igualdade Racial. Diretrizes Curriculares Nacionais para a Educação das Relações Étnico- Raciais e para o Ensino de História e Cultura Afro-Brasileira e Africana. Brasília: DF, 2005.

BRASIL. Decreto No 4.887, DE 20 DE NOVEMBRO DE 2003. Regulamenta o procedimento para identificação, reconhecimento, delimitação, demarcação e titulação das terras ocupadas por remanescentes das comunidades dos quilombos de que trata o art. 68 do Ato das Disposições Constitucionais Transitórias. DECRETO DO EXECUTIVO, Brasília, DF, 20 nov. 2003. 182o da Independência e 115o da República. Disponível em:

http://www.planalto.gov.br/ccivil_03/decreto/2003/d4887.htm Acesso em: 10 ago. 2018.

BRASIL. Lei no 10.639 de 09 de janeiro de 2003. Brasília: Presidência da República, 2003. Disponível em: http://www.planalto.gov.br/ccivil_03/Leis/2003/L10.639.htm Acesso em 21 de set. de 2018.

BRASIL. Lei no 11.645 de 10 de março de 2008. Brasília: Presidência da República, 2008. Disponível em: http://www.planalto.gov.br/ccivil_03/_Ato2007-2010/2008/Lei/L11645.htm Acesso em 21de set. de 2018.

BRASIL. Fundação Cultural Palmares. Comunidades Quilombolas. Disponível em: http://www.palmares.gov.br/?page id=37551. Acesso em 30 de jun. 2018.

CARDOSO, Luis Fernando Cardoso e. Reconhecimento e organização política quilombola na luta por território na Ilha do Marajó (PA). Dossiê rural - Dinâmicas contemporâneas do mundo rural, Cronos: R. Pós-grad. Ci. Soc. UFRN, Natal, v.14, n.2, 2013 (p. 93-107).

DUTRA, Nivaldo Osvaldo. Liberdade é reconhecer que estamos no que é nosso: comunidades negras do Rio das Rãs e da Brasileira - BA (1982-2004). 2007. 178 f. Dissertação (Mestrado em História) - Pontifícia Universidade Católica de São Paulo, São Paulo, 2007.

FREITAS, Décio. O Escravismo Brasileiro. Porto Alegre: Mercado Aberto, 1982.

FUNDAÇÃO CULTURAL PALMARES. Comunidades Quilombolas. Disponível em: http://www.palmares.gov.br/?page_id=37551. Acesso em 30 de jun. de 2018.

GOHN, Maria da Glória. O protagonismo da sociedade civil: movimentos sociais, ONGs e redes solidárias. 2. ed., São Paulo: Cortez, 2008.

GOMES, Nilma Lino. Alguns termos e conceitos presentes no debate sobre relações raciais no Brasil: uma breve discussão. In: Educação anti-racista : caminhos abertos pela Lei 
Federal n 10.639/03 / Secretaria de Educação Continuada, Alfabetização e Diversidade. Brasília: Ministério da Educação, Coleção Educação para todos, 2005 (p. 39-62).

GOULARTE, Nivaldo Aníbal. Brasil 500 anos: desconstruindo o mito (coletânea de textos). Criciúma: Unesc, 2000.

LE GOFF. História e Memória. 7ed. São Paulo: Unicamp, 2003.

LEITE, Ilka Boaventuura. Os quilombos no Brasil: questões conceituais e normativas. In: Etnográfica, v. IV, n. 2, 2000 ( p. 333-354).

LEITE, Ilka Boaventuura. O projeto político quilombola: desafios, conquistas e impasses atuais in Rev.Estud.Fem.vol.16.n³ Florianópolis. set. /dez.2008.

MACÊDO, Dinalva de Jesus Santana. Educação em Comunidades Quilombolas do Território de Identidade do Velho Chico/BA: indagações acerca do diálogo entre as escolas e as comunidades locais. Tese de doutorado. Universidade do Estado da Bahia, 2015.

MOURA, Clovis. Os Quilombos e a Rebelião Negra. São Paulo. Ed. Brasiliense, $5^{\text {aed. }} 1986$.

MOURA, Clovis. Quilombos: resistência ao escravismo. São Paulo: Ática, 1987.

MUNANGA, Kabengele. Identidade, cidadania e democracia: algumas reflexões sobre os discursos anti-racistas no Brasil.In: SPINK, Mary Jane Paris(Org.) A cidadania em construção: uma reflexão transdisciplinar. São Paulo: Cortez, 1994 ( p. 177-187).

MUNANGA, Kabengele. Origem e histórico do quilombo em África. In: MOURA, Clóvis. Os quilombos na dinâmica social do Brasil. Maceió: EDUFAL, 2001(p. 21-31).

MUNANGA, Kabengele. Uma abordagem conceitual das noções de raças, racismo, identidade e etnia. Palestra pproferida no $3^{\circ}$ Seminário Nacional Relações Raciais e Educação - PENESB-RJ, 05 de novembro de 2003.

POLLAK, Michael. Memória, esquecimento, silêncio. Estudos Históricos, Rio de Janeiro, vol. 2, n. 3, 1989 ( p. 3-15).

PRIOSTE, Fernando, Gallardo Vieira, Quilombolas, Luta, por Terras e Questões Raciais no Supremo Tribumal Federal. In: Os direitos territoriais quilombolas: além do marco territorial/ Coordenadores, Antonio Carlos Wolkmer, Carlos Frederico Marés de Souza Filho, Maria Cristina Vidotte Blanco Tarrega..-- Goiânia : Ed. da PUC Goiás, 2016. (p. 105 - 124).

SANTOS, Jamille Pereira Pimentel. As etnicidades geracionais presentes na dinâmica do nascer, viver e morrer na comunidade quilombola Queimadas, Guanambi/Ba".

Dissertação. (Mestrado em Relações Étnicas e Contemporaneidade) Universidade Estadual do Sudoeste da Bahia - UESB.- Jequié, 2017.

SILVA, Valdélio Santos. Rio das Rãs a luz da noção de quilombo. Revista Afro- Ásia. 23 n. Salvador: EDUFBA. 2000 (p. 267-295). 
SILVA, Joseane Maia Santos. Comunidades quilombolas, suas lutas, sonhos e utopias.

Revista Palmares - Cultura Afro-brasileira. A FCP chega aos 21 anos - Tempo de cidadania e diversidade. Ano V, n. 5, ago. 2009.

\section{SOBRE AS AUTORAS:}

\section{Hayla Fernanda Moura Lima:}

Licenciada em Pedagogia pela Universidade do Estado da Bahia e Especialista em Educação do Campo pela Universidade do Estado da Bahia (UNEB). Departamento de Educação, Campus XII de Guanambi/BA. E-mail: haylamoura03@gmail.com

iD http://orcid.org/0000-0002-8555-5966

\section{Dinalva de Jesus Santana Macêdo}

Doutora em Educação e Contemporaneidade. Professora Adjunta da Universidade do Estado da Bahia- UNEB. Departamento de Educação, Campus XII de Guanambi-Ba. Pesquisadora vinculada ao Núcleo de Estudo, Pesquisa e Extensão Educacional Paulo Freire- NEPE. Linha de Pesquisa: Currículo, diversidade e formação docente. Professora do Programa de PósGraduação em Educação da Universidade Estadual do Sudoeste da Bahia - PPGED UESB, Campus de Vitória da Conquista, vinculada à Linha 2 de pesquisa- Currículo, prática educativa e diferença. E-mail: dinalvamacedo@ hotmail.com

(iD http://orcid.org/0000-0001-8702-5048

Recebido em: 04 de dezembro de 2019 